\title{
Resenha
}

\section{O Sagrado em questão: uma análise a partir da fenomenologia da Religião}

\author{
El sagrado en cuestión: una análisis a partir de la \\ fenomenología de la religión
}

The sacred in question: an analysis from the phenomenology of religion

\section{Felipe de Queiroz Souto}

ALES BELLO, Angela. O Sentido do Sagrado da arcaicidade à dessacralização. Tradução de Paulo Sérgio Lopes Gonçalves e Dilson Daldoce Júnior. São Paulo: Paulus, 2018 Coleção Mundo da vida / Coordenação de Márcio L. Fernandes.

A filósofa italiana Angela Ales Bello publicou em 2014 na Itália a sua obra Il senso del sacro: dall'arcaicità alla desacralizzacione, texto que foi traduzido no Brasil por Paulo Sérgio Lopes Gonçalves e Dilson Daldoce Júnior e publicado pela Paulus em 2018 com o título O sentido do sagrado da arcaicidade à dessacralização na coleção Mundo da vida organizado por Márcio Luiz Fernandes. A proposta da autora em seu livro é a de analisar através da fenomenologia o aspecto do sacro nas religiões arcaicas até a sua constituição nas religiões complexas. A fenomenologia operada por Ales Bello tem seu desenvolvimento sobre a filosofia de Edmund Husserl e de Edith Stein, os principais referenciais teóricos da autora. Junto a eles, Ales Bello considera que o trabalho fenomenológico necessita do aporte teórico đa antropologia e da história para compor seus resultados. Por essa razão, ela se apropria da antropologia estruturalista de Lévi-Strauss para uma análise 
mais precisa culturalmente dos objetos sagrados. Ela desenvolve, com isso, uma fenomenologia da religião a partir de uma descrição histórico-filosófica que se utiliza da história das religiões (p. 33).

Justifica-se o objetivo da autora no texto com o fato de que, se por um lado, houve a emergência de um pensamento pós-moderno que se identificou com o sagrado após a afirmação heideggeriana de que "só um Deus pode nos salvar", de outro houve um modo de pensamento que envolveu todo tipo de conteúdo possível dentro do conceito de sacralidade (p. 15-16), banalizando assim a compreensão do termo. Resultado destes processos foram análises superficiais a respeito da questão do sacro. Ales Bello preocupa-se, portanto, em resgatar o sentido do sagrado para as culturas arcaicas através da antropologia e da fenomenologia, para então, identificar as estruturas fundamentais da experiência humana e para responder à distinção existente entre o sagrado e o religioso, duas esferas que compõe a experiência humana no modo de compreender o divino.

Ainda em termos de justificativa, a própria autora considera que transcorrer o percurso das diversas compreensões que o sagrado arcaico possuía nas antigas culturas é um trabalho que nos auxilia a "evidenciar as estruturas das religiões que nos são mais próximas" (p. 17), ajudando-nos até a compreender o fenômeno de dessacralização que caracteriza o mundo contemporâneo. Nesta perspectiva, o caminho percorrido por Ales Bello não é o de uma "reconstrução histórico-sistemática" (p. 18) do fenômeno do sagrado nas experiências religiosas, mas antes leva adiante o intento de compreender as características fundamentais da manifestação sacrorreligiosa na estrutura humana e social, operando de modo teorético - e nos parece o único possível - a fenomenologia da religião.

O livro está dividido em duas partes, sendo a primeira parte denominada de Arqueologia fenomenológica do sagrado e a segunda parte denominada de Arqueologia do Sagrado Complexo. A obra ainda acompanha uma premissa introdutória da autora justificando a importância da análise fenomenológica da experiência religiosa, bem como propõe a distinção entre os conceitos de bylética e de noética como categorias para a análise da experiência religiosa. Em termos conclusivos, a autora elaborou um epílogo no qual discorre sobre o sentido da dessacralização em perspectiva antropológica. Para uma apresentação à edição brasileira o tradutor Paulo Sérgio Lopes Gonçalves e o organizador da coleção Márcio Luiz Fernandes estruturaram brevemente o caminho dos estudos da religião entre o século 
XIX e XX e já anunciam que é a "pluralidade analítica" (p. 11) presente na contemporaneidade o fator de motivação de Angela Ales Bello para uma fenomenologia em diálogo com a história e com a antropologia. Deste modo, o que faz autora com o auxílio da fenomenologia é também uma antropologia cultural, a qual dá o fundamento para uma análise das mitologias e das religiões dos povos arcaicos.

Como já anunciado, a filósofa italiana articula sua leitura fenomenológica operando com os conceitos de bylética e noética que podem ser entendidos como momentos que compõe o fenômeno religioso enquanto uma experiência de vida vivida, isto é, de vivência (Erlebnis). Nesta perspectiva, bylética e noética são estruturas constitutivas da experiência humana. A primeira corresponde ao que é próprio da materialidade da vivência, enquanto a segunda corresponde ao que dá sentido à materialidade, pois reflete o caráter numênico da experiência. É a noética que está aberta à ação da Potência. A Potência pode ser compreendia como o fator religioso com o qual o fiel faz sua experiência e ela pode manifestar-se de diversas formas de acordo com a vivência daquele que a experiencia: o homo religiosus (p. 32). Para a fenomenologia da religião, a autora considera que o bylético se assemelha ao religioso enquanto o noético se assemelha ao sacro.

O que faz Ales Bello é perceber nas formas arcaicas da manifestação do sagrado a presença do bylético e do noético já que toda experiência que se faz da Potência possui uma articulação bylética e uma articulação noética. Temos, portanto, que o momento bylético é sempre acompanhado da presença da noética, já que um significado sempre acompanha seu significante. Seguindo estas distinções, na primeira parte do livro a autora estuda de modo arqueológico a forma de representação do sagrado nas culturas arcaicas, desenvolvendo uma leitura desde 1) os sinais do sagrados e os objetos sacros, 2) a formação do sacrifício como o rito do sacro facere - tornar sagrado -, 3) o significado do alimento durante o rito sagrado até 4) a representação do mal.

Para a análise dos sinais do sagrado a filósofa recorre a Lévi-Strauss que a ajuda a perceber a indistinção entre os ser e aparecer, sujeito e objeto, sinal e ente nas culturas arcaicas. O que há nelas é a conformidade entre a atividade humana e o seu significado sagrado, de modo que toda a vida humana “é permeada por um 'sentimento' de sacralidade” (p. 48) não havendo distinção entre espírito e natureza. A realidade está envolvida na totalidade da Potência. Ressalta a autora que este envolvimento próprio da arcaicidade é difícil de ser compreendido pela nossa cultura que distingue os eventos 
sacros da realidade corpórea. Sobre os objetos sacros, sendo analisados pelos mesmos critérios da fenomenologia, ela afirma que a "sacralidade é sempre própria do objeto considerado em si mesmo" (p. 53), isso porque ele representa o momento bylético da manifestação noética.

Em termos elucidativos, Ales Bello, tomando de Lévi-Strauss, traz o rito funerário dos Aranda, uma tribo da Austrália Central, que possuem em sua liturgia objetos de pedra ou de madeira marcados com sinais simbólicos chamados de churinga. A churinga representa o corpo físico de um dos ancestrais da tribo e funciona como um "arquivo histórico" em que se conserva a presença do falecido mesmo com o passar do tempo. A autora entende que a churinga é o aspecto bylético da relação com o sagrado pois ela carrega em si algo de noético que é a memória, a afetividade, o significado (p. 52). É fato que fenômenos como esses na mentalidade arcaica não se constituem como realidades distintas, mas se dão como estrutura de uma mesma vivência, articulando bylética, noética e sacralidade (p. 53).

Ao que corresponde ao sacrifício, a filósofa identifica o aspecto essencial do rito religioso que pode ser compreendido a partir de sua formulação latina de sacrificium, denotativo de sacra facere, isto é, o ato de tornar algo sagrado, de "cumprir ações sagradas" (p. 57). Aproximando-se da semiótica e da semântica de Émile Benveniste a autora constitui brevemente a noção linguística de sagrado nas tradições arcaicas para compor o quadro de análise da manifestação religiosa. Assim, tem a compreensão de que a raiz latina sak que está no adjetivo itálico sakri, deriva a palavra sacer e tem o seu significado na relação com o termo latino sanctus. Ambas palavras derivam da mesma raiz, mas possuem sentidos distintos. Para sacer, tem-se aquilo que está em relação com o divino. Para sanctus, tem-se o sentido do verbo sancire, isto é "a operação humana de estabelecer os limites e os confins daquilo que é sacer" (p. 60).

Também a partir da língua grega pode-se observar algumas aproximações, como: o hierós, que se refere a ação anterior da Potência, compartilha seu significado com o spenta do avênico e com o hailig - de onde deriva heilig na língua alemã - do rúnico. O termo em questão indica a "Potência que dá saúde" (p. 61). De qualquer modo, sendo a partir dos termos latinos ou do grego, as incursões no campo da semântica mostram que "no fundo da experiência sacrorreligiosa se encontra a presença de uma abertura pessoal-coletiva na direção da Potência que dá sentido às coisas e à vida humana" (p. 62), uma abertura que se comporta de modos diferentes no decorrer da história da humanidade mas que sempre desenvolveu sua 
confiança em uma "salvação meta-histórica" (p. 62). Estabelecendo a distinção dessas manifestações entre o sagrado arcaico e o sagrado complexo, podemos observar na leitura de Ales Bello os seguintes aspectos: a sacralidade está condicionada com a visão de mundo e as ações humanas estão articuladas nas ações da Potência para o sagrado arcaico, de modo que é difícil delimitar e compreender os momentos de bylética e de noética. Enquanto no sacro complexo, bylética e noética estão diversamente balanceados (p. 68), dando mais espaço ao momento noético de forma que o desenvolvimento histórico das culturas permite que o momento bylético vá perdendo a sua força (p. 69).

Uma das formas mais populares das tradições religiosas são as práticas alimentares durante o rito, denominados por banquete ritual que é um "momento emblemático, excepcional, mas reforçador de todo outro banquete, porque dá a salvação, no duplo significado de manutenção da vida física e de resgate da morte, não daquela que diz respeito ao indivíduo, mas ao grupo inteiro que pratica o rito" (p. 77). Para elucidar a citação, podemos tomar o exemplo da própria autora que cita a tradição dos Yurok, uma cultura indígena do norte da América, qual celebrava seu banquete sagrado com o salmão. Acreditava-se que o salmão fosse imortal por sua nobreza, confundindo os dois momentos: ser imortal e peixe (p. 78). O rito era composto por quatro pessoas, o ancião que desenvolve as orações com a função de sacerdote, a mulher anciã que corta o salmão, a menina que cozinha o peixe sobre o fogo e o coloca sobre uma camada de angélica e o jovem que que deve comer o salmão e ganhará a força da divindade. Também no sagrado complexo o banquete aparece de forma primordial, no cristianismo a divindade assume a forma da matéria através da eucaristia e denota a presença da própria divindade que confere redenção e salvação ao fiel no ato de comer o corpo e beber o sangue do Redentor. Novamente, a noética passa a conferir sentido à bylética.

Sobre a compreensão do mal, Ales Bello segue a compreensão de Gerardus van der Leeuw, e entende - ainda que amplamente - que todas as religiões estão voltadas para a salvação (p. 89). Salvação que se dá no livramento do mal. O mal denota a impotência humana, isto é, a limitação da existência do homem que só pode ser vencida na relação com a Potência. Esta preocupação está representada tanto nas religiões arcaicas quanto nas religiões complexas, concentrando-se de forma expressivamente estética e bylética na primeira e de forma mais espiritual e noética na segunda.

$\mathrm{Na}$ segunda parte do livro, Arqueologia do sagrado complexo, utilizando-se do instrumental teórico da fenomenologia de Edith Stein e de van der Leeuw, 
a autora analisa 1) a relação entre o fiel e o seu Deus, 2) a encarnação do divino e 3) a teologia negativa e mística em diálogo com Edith Stein. Sobre o primeiro ponto, ela parte da semântica que está construída no interior das culturas, o que torna ainda mais difícil a compreensão da Potência, que só pode ser entendida através da subjetividade humana dentro da objetividade da tradição na qual se revela. O fenomenólogo da religião jamais poderá ter a pretensão de totalidade, pois as variadas culturas experienciam variadas formas de representação do fenômeno religioso. Já que "a multiplicidade das divindades corresponde à multiplicidade dos rostos do divino diante das nossas possibilidades de compreendê-lo; de fato, não podemos jamais abarcálo na sua totalidade" (p. 106). No entanto, a subjetividade humana deve ser ponto de partida para o estudioso da religião interessado por compreender a manifestação da Potência. E, uma das formas mais comuns e denotativas de relação é a oração, prática presente em todas as religiões (p. 106) que revela o caráter de alteridade entre o ser humano e o Totalmente Outro a quem ele se dirige.

Também é fruto de investigação fenomenológica na obra de Ales Bello a manifestação do sagrado nas culturas politeístas, henoteístas e monoteístas, pois elas assumem diversas formas de caracterizar a divindade e, por isso, fragmentam a experiencia. No entanto, há um fio condutor entre as religiões que o fato de que é sempre a Potência que se revela e permite, de modo dialógico, a relação com o fiel que deseja o contato, a salvação, pela força criativa da Potência. A este modo de relação, a autora entende como uma relação de amor, expressa de forma mais presente na pessoalidade do Deus cristão (p. 121), que chama o ser humano à confiança. A experiência religiosa, portanto, é uma experiência amorosa. No capítulo dois, da segunda parte, sobre o espectro do cristianismo, Ales Bello analisa tomando as categorias de bylética e noética a encarnação do divino que entrega à matéria (bylética) uma noética, a "energia vital" (p. 125). De forma que a encarnação da divindade é a presença mesma da divindade.

No que diz respeito à teologia negativa e a mística, a autora compõe um diálogo com a fenomenologia de Edith Stein que, por sua vez, segue a teologia mística de Dionísio Aeropagita. Ales Bello entende que a teologia negativa é a bylética da mística, de modo que a primeira se denota como reflexão noética da segunda que é bylética (p. 133). A mística pode ser compreendida como uma experiência pessoal entre o fiel e a Potência. O fiel "sente" a ação do divino, o momento bylético, e o contempla como uma 
resposta do desejo. A contemplação mística revela a absoluta manifestação de Deus que "penetra no ser humano transformando-o" (p. 144), uma transformação que revela a Potência. Neste sentido, o que a autora assume é que a bylética e a noética como momentos fundamentais da experiência religiosa são também "vias para o conbecimento de Deus" (p. 144, grifo da autora).

No epílogo da obra a autora discute o processo de dessacralização do mundo contemporâneo, frente a composição do sagrado complexo. Ela afirma que a formação do pensamento ocidental nas vias do ateísmo teórico como de Feuerbach e Nietzsche insistiu por tirar o divino da experiência humana. No entanto, de contrapartida, Ales Bello entende que a experiência religiosa é uma experiência que "engloba as atividades espirituais humanas, portanto, também intelecto e vontade” (p. 147), algo que torna insuprimível a relação entre o homem e o sagrado, mas que pode se desenvolver sobre formas de substituição (p. 150). O sentido do sagrado é um texto de fenomenologia da religião e indispensável para todo estudioso da religião que queira compreender as formas da experiência religiosa na vivência cotidiana dos sujeitos. Utilizando-se da antropologia e da história, Ales Bello consegue fundamentar suas reflexões e situar seu discurso num horizonte histórico, o que permite uma análise responsável do objeto que é sempre diversa em cada cultura e em cada vivência humana.

Submetido em: 16-12-2019

Aceito em: 15-8-2020 